\title{
Religião e parentesco na colônia Castrolanda ${ }^{1}$
}

\author{
João Frederico Rickli \\ Mestre em Antropologia Social - UFPR
}

\begin{abstract}
RESUMO: Este artigo procura estabelecer um quadro sistemático das relaçôes entre religião e parentesco em Castrolanda - uma colônia de imigrantes holandeses no interior do Paraná. Por meio da descrição de alguns rituais da igreja e de aspectos do parentesco, como a divisão das famílias em quatro gerações, os critérios para esta divisão e o padrão dos casamentos e das alianças em cada uma delas, este trabalho busca compreender a relação entre o parentesco e a religião, apoiado em considerações teóricas tais como a noção de casa e de englobamento hierárquico.
\end{abstract}

PALAVRAS-CHAVE: religião, parentesco, casa, hierarquia.

Este artigo pretende analisar as articulações entre a religião e as relações de parentesco na colônia Castrolanda, por meio da apresentação de alguns dados acerca da igreja local, a Igreja Evangélica Reformada (IER), e da descrição de alguns de seus rituais, bem como pelos modos de classificação das relações familiares na comunidade e por uma análise de algumas especificidades dos casamentos no grupo.

Castrolanda está localizada a cerca de sete quilômetros da sede do município de Castro, distante 170 quilômetros de Curitiba, e foi fundada em novembro de 1951 por um grupo de agricultores cristãos holandeses vindos sobretudo de duas provínicias de base rural do nordeste da Holanda: Drenthe e Overijssel. Contava, no momento da conclusão 
de meu trabalho de campo ${ }^{2}$, com cerca de mil habitantes, e sua atividade econômica dominante é a agropecuária, organizada em torno da Cooperativa Castrolanda, à qual estão ligados quase todos os moradores da colônia, seja como produtores cooperados, seja como funcionários da cooperativa ou das chácaras e fazendas a ela associadas. Há duas escolas e duas igrejas na região de Castrolanda: de um lado, a Escola Evangélica e a Igreja Evangélica Reformada; de outro, a Escola Estadual e a Igreja Católica. Em termos gerais, pode-se afirmar que as primeiras reúnem os imigrantes e seus descendentes e as últimas são formadas pelas famílias "brasileiras"', compostas principalmente pelos funcionários das chácaras e da cooperativa. Além dessas duas escolas, há a Escola Holandesa Prins Willem Alexander, inaugurada pelo príncipe dos Países Baixos em sua visita ao Brasil em 1998, que complementa as atividades da Escola Evangélica com aulas de holandês, geografia e história da Holanda, além de promover atividades que visam à preservação das tradiçôes holandesas em Castrolanda.

Este trabalho parte da descrição, por um lado, de alguns rituais da Igreja Evangélica Reformada e, por outro, do modo como, em Castrolanda, definem-se as relaçóes de parentesco, com o objetivo de compreender como se dá a articulação entre estes dois domínios. Para tanto, utilizo-me da noção de "casa" (Lévi-Strauss, 1979 e 1983), cuja formulação, enquanto estrutura jurídica, política, moral, expressa na linguagem do parentesco fornece um modelo analítico que possibilita a aproximação entre religião e parentesco. Por meio da conjugação desse modelo com a noção de englobamento hierárquico (Dumont, 1997; 2000a; 2000b), pretendo explicitar como, em Castrolanda, a igreja, enquanto termo englobante em relação ao parentesco, determina as fronteiras e as condiçôes de pertença e acesso ao grupo ${ }^{4}$. 


\section{A Igreja Evangélica Reformada de Castrolanda}

Em outubro de 1952, ainda durante o período de formação da colônia, antes da chegada de todos os imigrantes, foi formalmente organizada a igreja reformada, conforme a decisão tomada nas reuniōes preparatórias da emigração, na Holanda. Segundo o relato da Sra. Kiers ${ }^{5}$ (Kiers-Pot, 2001, p. 86), 90\% dos futuros imigrantes pertenciam a uma das três principais denominações reformadas calvinistas holandesas: a Gereformeerde Kerk, a Nederlans Hervormde Kerk e a Christelijk Gereformeerde $K e r k^{6}$. O próprio movimento de emigração que deu origem à colônia holandesa em Castro e os acordos com o governo brasileiro foram encabeçados por duas entidades ligadas às igrejas reformadas - a Christelijk Emigratie Centrale (Central Cristã de Emigração) e a Christelijk Boeren en Tuinders Bond (Associação Cristã de Granjeiros e Horticultores). Também a seleção dos futuros imigrantes foi realizada pelo diretor de uma escola protestante, o Sr. Kaemingk, diretor da Escola Cristã de Agricultura em Hoogeveen, no norte da Holanda. O primeiro pastor foi William Muller, que residia em Carambeí, outra colônia holandesa no Paraná, formada em 1911 em condições muito distintas das de Castrolanda. Esse pastor tinha trabalhado anteriormente na Christian Reformed Church, a igreja dos imigrantes holandeses na América do Norte, e era também cônsul honorário dos Países Baixos na região, desempenhando um papel importante nas negociações para a imigração. Foi também o primeiro presidente da Cooperativa Castrolanda.

Em 1962, as igrejas reformadas de origem holandesa, no Brasil e na Argentina, tornaram-se independentes de suas matrizes européias, e a Igreja Evangélica Reformada (IER) tornou-se uma denominação reconhecida por elas como "igreja irmã”. Em 2001, havia no Brasil sete IERs: Castrolanda (PR); Carambeí - Colônia (PR); Vila Nova Holanda, em

Carambeí (PR); Arapoti (PR); Tibagi (PR); São Paulo; e Balsas (MA). 
Havia ainda uma comunidade em Curitiba (PR) que, por ser formada principalmente por estudantes universitários castrolandeses, estava sob responsabilidade da IER de Castrolanda e em processo de emancipação. Todas participam do Sínodo das IERs, que se reúne duas vezes por ano e delibera acerca de atividades conjuntas e questôes de interesse geral. A IER de Castrolanda contava, em 2001, com aproximadamente 709 membros, sendo 360 professos $^{7}$ e 349 batizados. Desenvolve um grande número de atividades, além dos cultos dominicais, e é gerida por diversas comissões e organizações, dentre as quais o Conselho, que descrevo a seguir, é a mais importante.

O Conselho da Igreja Evangélica Reformada de Castrolanda é o órgão máximo da igreja. É formado por dez presbíteros, quatro diáconos e pelos pastores ${ }^{8}$, que se reúnem uma vez por mês, ordinariamente. Os membros do Conselho são eleitos pelos membros professos da igreja em dois turnos, realizados em rápidas assembléias convocadas após o culto matinal. No primeiro, todos os membros da igreja indicam candidatos, escolhidos entre os membros professos, para concorrerem às vagas abertas. Os nomes que receberam o maior número de indicaçóes tornam-se candidatos. No segundo turno, os membros professos escolhem, pelo voto, os novos presbíteros e diáconos. Os "mandatos" duram três anos, mas o próprio Conselho pode solicitar a algum de seus membros que permaneça por mais tempo, quando há muitos mandatos vencendo num mesmo período. As eleiçôes realizam-se sempre que há presbíteros ou diáconos completando os três anos previamente fixados, o que acontece, na prática, todos os anos.

São elegíveis para o Conselho todos os membros professos da igreja, com duas ressalvas: o número de mulheres presbíteras não deve ser superior ao de homens ${ }^{9}$ e não pode haver duas pessoas da mesma família ocupando assentos simultaneamente no Conselho. São considerados da mesma família os pais (F e M), os filhos ( $\mathrm{S}$ e D), os irmãos (B e Z), os 
cônjuges (W e H), os avós (FF, MF, FM e MM) e os netos (SS, DS, SD e DD). Não há nenhum impedimento formal aos sogros e sogras (HF, HM, WF, WM) e aos genros e noras (SW e DH), entretanto nunca ocorreram casos deste tipo e, de acordo com opiniōes ouvidas em campo, causaria um certo desconforto a eleição de alguém ligado por um destes laços a algum dos membros do Conselho.

Cada um dos presbíteros, com exceção do secretário e do presbítero de jovens, torna-se responsável por um dos oito bairros em que a colônia está dividida ${ }^{10}$. Além disso, cada um recebe atribuições específicas, desenvolvendo um tipo diferente de atividade, seja auxiliando e supervisionando os trabalhos das demais comissões internas da igreja, seja representando a IER externamente, junto a outras igrejas ou entidades com as quais ela colabora. Os diáconos têm a responsabilidade de zelar pelo patrimônio da igreja, atender para que tudo corra bem durante os cultos e recolher as ofertas. São também eles que distribuem os carnês de contribuição financeira, a parte mais significativa do orçamento da igreja. Embora todos participem igualmente das reuniōes, há uma diferença hierárquica entre presbíteros e diáconos. Os segundos são em geral mais jovens, e seu serviço é considerado mais leve do que o dos primeiros, que atendem diretamente os moradores do bairro pelo qual são responsáveis, visitando-os ao menos uma vez por ano, aconselhando-os quando necessário e assistindo-lhes, junto com os pastores, em problemas familiares e espirituais.

O secretário do Conselho é ainda responsável por organizar o Guia da Comunidade (IER de Castrolanda, 2002), uma publicação atualizada a cada dois ou três anos, no qual constam uma breve descrição das principais comissóes e atividades da igreja, indicando o nome das pessoas responsáveis por elas, uma lista com o endereço e o telefone de todos os membros, em ordem alfabética, uma lista com o aniversário de todos os membros, em ordem de data, e, finalmente, uma lista de famílias por 
bairros. O guia é largamente usado por todos, funcionando principalmente como lista telefônica e agenda de aniversários.

As atribuiçôes do Conselho como um todo são administrativas e eclesiásticas, cabendo aos seus membros deliberar, junto com os pastores, tanto sobre questōes práticas ligadas ao gerenciamento das atividades da igreja, quanto sobre questōes teológicas e espirituais, além de eventuais (e raríssimas) admoestações de caráter disciplinar. O Conselho é o único responsável pela principal atividade da igreja: os cultos, sendo a organização destes de sua alçada exclusiva, como é expresso pelo próprio rito, conforme veremos.

Os cultos da IER de Castrolanda têm uma estrutura bastante rígida e repetitiva. Acontecem todos os domingos, às $9 \mathrm{~h} 30 \mathrm{e}$ às $19 \mathrm{~h} 30$. Os mais freqüentados são os matutinos, nos quais o templo, com capacidade para aproximadamente 360 pessoas, fica normalmente cheio, enquanto nos vespertinos, usualmente, comparecem cerca de 100 pessoas. Os cultos duram, em geral, entre 60 e 80 minutos, e se iniciam com o cântico de um hino de entrada, durante o qual o pastor e os presbíteros entram no templo "em cortejo", vindos da sala do Conselho, cuja porta fica na lateral da igreja. Em frente ao púlpito, o "presbítero de plantão", responsável pelos cultos do dia, cumprimenta o pastor e senta-se no primeiro banco, invariavelmente vazio. Os demais presbíteros dirigem-se aos seus bancos habituais, junto com suas famílias ${ }^{11}$. $\mathrm{O}$ pastor encaminha-se à mesa, de onde dirige boa parte do serviço. A liturgia reformada tem como ponto central a palavra de Deus, e não o sacrifício da eucaristia, como é o caso da religião católica. Por isso, a parte frontal do templo reformado tem o púlpito, o lugar da palavra, ao centro. Não há um altar, que remete à idéia do sacrifício da Eucaristia, mas sim uma mesa, de onde o pastor dirige a liturgia. Quando há celebração da Eucaristia, o que ocorre cinco vezes durante o ano, afastam-se os primeiros bancos e uma grande mesa é disposta ali, ao redor da qual se sentam os fiéis. 
O pastor saúda os presentes, em nome do Conselho, e dá a benção inicial. Normalmente se canta uma doxologia ${ }^{12}$, ou um salmo de louvor. Em seguida, há um momento de contrição e arrependimento e de anúncio do perdão e da graça divina. Nesse instante, o pastor chama à frente as crianças que irão à Escola Dominical para que se aproximem da mesa, e lhes dirige algumas palavras rápidas, contando uma pequena história ou falando algo relacionado aos textos da pregação do dia. Uma das crianças traz uma vela, que o pastor acende na Vela Pascal, que sempre queima diante do púlpito, representando metaforicamente a presença da luz de Cristo na vida da igreja. Essa grande vela deve durar o ano todo e é substituída, no domingo de Páscoa, quando se celebra a ressurreição de Jesus. Já a vela carregada todos os domingos pelas crianças representa, por metonímia, a contigüidade entre o culto e a Escola Dominical. Seguem-se as leituras bíblicas, acompanhadas de um ou dois hinos, e então o pastor sobe ao púlpito, de onde faz a pregação. Após a pregação, canta-se mais um hino, e, com o pastor de volta à mesa, há uma longa oração de intercessão, chamada "oração pastoral", na qual são mencionados fatos do cotidiano da comunidade. $\mathrm{O}$ pastor faz então os "avisos do Conselho", os diáconos recolhem as ofertas em sacos de pano que circulam de mão em mão, e canta-se o hino final. O pastor impetra a Benção, e todos cantam "Amém". Com a comunidade em pé e em silêncio, o presbítero cumprimenta novamente o pastor, e o Conselho retorna para sua sala, com os diáconos levando os sacos com as ofertas. Depois que se fecha a porta, o organista toca e todos deixam o templo. A língua em que os cultos são realizados é questão de intensos debates na comunidade, e a distribuição de cultos matutinos e vespertinos em holandês e português entre os quatro ou cinco domingos do mês variou bastante durante o período de pesquisa. De um modo geral, podese dizer que paulatinamente a língua portuguesa passou a ser mais prestigiada, em detrimento da holandesa. No início da pesquisa, em 
1999, vigia uma distribuição mais ou menos eqüitativa, com uma leve tendência à língua holandesa (os cultos no quinto domingo do mês eram sempre em holandês). Já em 2003, os cultos matutinos, ou seja, aqueles realizados no horário de maior prestígio, eram em português, e os vespertinos em holandês, exceto no primeiro domingo do mês, quando o culto matinal era bilíngüe, com duas pregações, e o vespertino em português. Nas datas especiais, como Natal, Páscoa e Pentecostes, o culto matinal era também bilíngüe.

Uma vez descritos os cultos e a organização do Conselho da IER de Castrolanda, passo agora a descrever três rituais fundamentais da igreja e considerá-los em relação ao estabelecimento dos limites externos da comunidade e à formação, internamente, de diferentes grupos e categorias de membros.

A Profissão de Fé é realizada pelos jovens batizados na igreja por volta dos 21 anos, após freqüentarem, por um período que varia de seis a oito anos, as aulas de Catecismo, nas quais são instruídos sobre a doutrina e a fé da igreja. Para aqueles que ingressaram na igreja já adultos, caso que será detalhado adiante, há turmas especiais, nas quais é exigido um mínimo de dois anos de freqüência às aulas. A cerimônia é realizada normalmente uma vez ao ano, durante um culto matinal ordinário, antes da saída das crianças para a Escola Dominical, e dela participam os professandos que freqüentaram durante o ano a última classe do Catecismo. Consiste na leitura, pelo pastor, de uma Fórmula e do compromisso, pelos professandos, em seguir os preceitos aprendidos no Catecismo. O pastor abençoa cada um com imposição de mãos, e a comunidade canta hinos apropriados para a ocasião. $\mathrm{O}$ ato da Profissão de Fé divide os membros da igreja em duas categorias. A primeira é composta pelos professos, que já passaram pelo ritual, e têm direito a todos os atos, sacramentos e cargos na igreja; a segunda reúne aqueles denominados não professos, que não são considerados membros plenos, so- 
frendo algumas restrições em sua participação na comunidade. Embora eles possam, quando adultos, receber a Santa Ceia (Eucaristia), não podem votar nas eleições para membros do Conselho e na escolha de novos pastores, não podem batizar seus filhos, a menos que o cônjuge seja um membro professo, nem tampouco podem ser eleitos para o Conselho.

O Batismo na IER ocorre normalmente nos primeiros meses da vida da criança. É uma cerimônia bastante simples, que acontece também durante um culto normal, freqüentemente antes da pregação. A família (normalmente os pais, irmãos e uma das avós ou tias da criança) entra na igreja junto com o Conselho e com o pastor, pela porta lateral. Durante o culto, ela permanece no primeiro banco, com a avó (ou a tia) segurando a criança em seu colo. No momento da cerimônia do Batismo, propriamente, o pastor faz a leitura da Fórmula, intercalada com orações e cânticos. Os pais, em pé, respondem perguntas comprometendo-se a educar a criança dentro dos preceitos da igreja e, finalmente, o pastor chama o casal à pia batismal. A avó (ou tia) entrega a criança a um dos pais, eles se aproximam da pia, e o pastor verte um pouco de água sobre a cabeça do bebê, diz o nome completo da criança e a batiza em nome da Trindade. A comunidade participa cantando estrofes de hinos próprios para a ocasião, recitando o Credo Apostólico ${ }^{13}$ e respondendo afirmativamente a uma questão da Fórmula do Batismo sobre a aceitação do novo membro e a responsabilidade com seu desenvolvimento nos princípios da igreja.

Como já mencionado acima, uma criança só pode ser batizada na IER quando um de seus pais é membro professo da igreja. No caso de apenas um deles o ser, é este que irá conduzir a criança à pia batismal no momento do ritual, e são os seus parentes (a mãe ou irmã) que irão permanecer com a família no primeiro banco. As perguntas feitas àquele entre os pais que não é membro professo são também um pouco diferentes, dando um sentido de colaboração e apoio na tarefa de educar a 
criança de acordo com os preceitos da fé cristã, compromisso assumido por seu cônjuge professo. A IER aceita o batismo das outras igrejas, no caso de admitir membros adultos, vindos de outras comunidades. $\mathrm{Ne}$ nhum dos pastores entrevistados recordou-se de ter havido o batismo de um adulto. No final do culto, a família permanece próxima à pia batismal, onde recebe os cumprimentos de toda a comunidade, que faz uma longa fila no interior do templo, assim que o pastor e o presbítero de plantão se cumprimentam diante do púlpito.

Embora o culto de Casamento tenha praticamente a mesma estrutura do culto reformado regular, é o menos ordinário entre os três rituais descritos aqui. Quase nunca acontece num horário normal de culto; os noivos permanecem durante todo o culto em frente ao púlpito, não apenas no momento da cerimônia em si; são os noivos que escolhem o texto-base para a pregação e os hinos que serão cantados; e há uma entrada solene dos noivos, padrinhos e familiares, como normalmente acontece em outras igrejas neste tipo de cerimônia, com a diferença, entretanto, de que o pastor e o presbítero do bairro de um dos noivos também integram o cortejo. No caso de segundos casamentos, entre viúvos ou divorciados, contudo, é comum que a cerimônia ocorra no culto ordinário, no mesmo momento em que normalmente acontecem os batismos. A cerimônia é bastante semelhante à da Igreja Católica, com a leitura da Fórmula, juramento dos noivos, troca de alianças e benção matrimonial, com os noivos ajoelhados diante do pastor. $\mathrm{O}$ final do culto matrimonial, entretanto, difere bastante do casamento católico, havendo recolhimento de ofertas, como nos cultos ordinários, e a entrega, pelo presbítero do bairro de um dos noivos, de uma Bíblia, como um presente da comunidade à nova família que se constitui na cerimônia. Normalmente é o noivo quem recebe a Bíblia, entretanto, em dois casamentos que presenciei, nos quais o noivo era de fora, ela foi entre- 
gue à noiva. Na saída, os noivos e seus pais se colocam à porta e recebem, assim como no Batismo, os cumprimentos de toda a comunidade.

Partindo dos dados apresentados acerca do Conselho e dos principais rituais da igreja, é possível estabelecer um modelo da organização social da IER, para posteriormente confrontá-lo com a descrição das relaçôes de parentesco. Em primeiro lugar, é evidente o papel preponderante do Conselho como centro do poder na comunidade, fato expresso de muitas maneiras no modo de encaminhamento dos ritos. No culto, a entrada e saída de seus membros é parte do ritual, e é feita por uma porta exclusiva, diferente da dos demais membros. Embora seja o pastor quem ministre os ritos, é o Conselho da igreja quem dá a permissão para que ocorram. No caso do Batismo, os pais devem comunicar formalmente o Conselho, por meio do presbítero responsável pelo "bairro" onde moram, que desejam batizar o recém-nascido. Uma semana antes, durante o culto o pastor, nos momentos dos "avisos do Conselho", anuncia à comunidade que, no próximo domingo, conforme a solicitação dos pais, a criança será batizada. No caso do Casamento, os noivos devem procurar o presbítero do bairro onde um deles mora para solicitar que o Conselho examine o pedido e dê a permissão para que a cerimônia se realize. O Conselho se reúne e caso decida positivamente, o que praticamente sempre acontece, anuncia, num dos cultos, a realização da cerimônia. Para a Profissão de Fé, após os anos de Catecismo, cada um dos alunos submetia-se a uma avaliação oral, numa reunião com um dos pastores e alguns presbíteros, onde respondia perguntas sobre os conteúdos do Catecismo e sobre questóes de sua fé particular. Em anos recentes, essa prática caiu em desuso, substituída por uma conversa mais informal entre o pastor, um presbítero e o professando. Todos esses ritos e práticas expressam a soberania do Conselho na comunidade. 
A própria posição do pastor na IER merece uma análise mais detalhada. $\mathrm{O}$ seu poder para operar e dirigir os ritos provém do ato da Ordenação, que permite que realize os dois únicos sacramentos da IER, o Batismo e a Santa Ceia ${ }^{14}$, e que fale e abençoe em nome de Deus e da Trindade, sacralizando os rituais que descrevemos. O Conselho da igreja se apropria desse poder ao contratá-lo, e é isto que os ritos de entrada e saída do Conselho e do pastor nos cultos expressam. O pastor é praticamente conduzido ao púlpito pelo presbítero que, ao cumprimentá-lo em frente à comunidade, renova o pacto entre o poder reconhecido como divino, adquirido pelo pastor ao ordenar-se, e o poder secular do Conselho como condutor da vida comunitária. É esse pacto entre poderes divino e secular que permite que os rituais de Batismo, Profissão de Fé e Casamento estabeleçam categorias entre os membros da IER.

De acordo com um dos pastores da colônia, o casamento é praticamente o único motivo de ingresso de novos membros adultos na IER de Castrolanda, o que se confirma por observações em campo. O número de membros transferidos de outra igreja por qualquer outro motivo, ou de convertidos à fé reformada que se tornam membros em Castrolanda, é desprezível, não chegando a dez pessoas, num universo de mais de 700 membros. Disso se depreende que há apenas dois rituais por meio dos quais alguém passa a integrar a IER de Castrolanda: o Batismo para os ali nascidos e o Casamento para aqueles que vêm de fora. Com exceção desses poucos casos de transferidos ou convertidos citados pelo pastor, não há quem freqüente a igreja e que não tenha passado por algum destes rituais na própria IER. Se pensarmos agora que o Batismo e o Casamento só são concedidos a filhos ou cônjuges de professos, veremos que só passam a integrar a igreja indivíduos que se liguem por filiação, no caso do Batismo, ou por aliança, no caso do Casamento, a alguém que já tenha feito a sua Profissão de Fé. Essa afirmação nos leva a algumas conclusões importantes. Primeiramente, o 
papel fundamental, do ponto de vista da organização social, desempenhado pelo rito da Profissão de Fé. Sendo condição necessária para a realização dos dois únicos rituais de acesso à comunidade, ele define os seus limites externos. Uma segunda conclusão notável, que será desenvolvida adiante, é a importância capital que as relações de parentesco assumem na questão do pertencimento ao grupo.

Neste ponto, poderíamos visualizar a IER de Castrolanda como uma estrutura de dois círculos concêntricos: o mais interno contendo os membros professos, o mais externo, os que ingressaram na igreja pela via do Batismo ou pela via do Casamento, por meio de uma relação de parentesco (filiação e aliança, respectivamente) com alguém do primeiro círculo, mas que ainda não realizaram a sua Profissão de Fé.

Um próximo passo na análise seria a justaposição dos grupos diferenciados por esses três rituais, extraindo daí categorias de membros, de acordo com as combinações possíveis. Chegaríamos a cinco categorias: (1) os batizados, professos e casados; (2) os batizados, professos e nãocasados; (3) os batizados, não-professos e não-casados; (4) os não-batizados, professos e casados; e (5) os não-batizados, não-professos e casados ${ }^{15}$. Duas combinações são impossíveis, ou muito raras: os não-batizados, não-casados e professos; e os não-batizados, não-casados e não-professos. Elas não ocorrem, ou só ocorrem raramente, por serem o Batismo ou o Casamento os dois únicos meios de acesso à igreja. Portanto, não se verifica a ocorrência de membros não-batizados e não-casados, exceto por aqueles poucos membros transferidos já citados. Há uma última combinação, a dos batizados, não-professos e casados que, embora possível, raramente ocorre, por ser a Profissão de Fé costumeiramente obrigatória aos jovens batizados em Castrolanda.

De acordo com os dados descritos até aqui, podemos alinhar as cinco categorias de membros num continuum com três estágios, traçado imaginariamente de fora para dentro da igreja. O primeiro estágio, o 
mais externo, coincide com o círculo dos membros não-professos, e nele estariam os somente batizados e os somente casados, ou seja, crianças e jovens e aqueles que vêm de fora e ainda não passaram pela Profissão de Fé. No estágio mais interno estariam os batizados, professos e casados, grupo no qual se incluem os adultos nascidos em Castrolanda e ali casados, membros plenos da comunidade ${ }^{16}$. No estágio intermediário, mediando a oposição entre os membros professos plenos e os não-professos, estariam os somente batizados e professos e os somente casados e professos, ou seja, os castrolandeses adultos e solteiros e os não-castrolandeses casados que, após os dois anos de Catecismo, optaram por se tornar professos. Dentro deste segundo estágio seria possível, ainda, afirmar que o grupo dos somente batizados e professos é mais interno do que o dos somente casados e professos, pois enquanto estes últimos estão permanentemente posicionados no estágio intermediário, os primeiros podem ainda, pelo casamento, atingir o estágio mais interno do continuum.

As diferenças entre essas três categorias estariam expressas nos diferentes cargos e funções que as pessoas pertencentes a cada uma delas tradicionalmente ocupam. Embora a princípio todos os professos possam ser eleitos para o Conselho, todos os seus membros são pessoas batizadas e casadas em Castrolanda. Não há nenhum presbítero solteiro nem tampouco um que tenha entrado na igreja pelo Casamento. A única exceção é uma mulher batizada e professa, porém solteira, que ocupava a posição de presbítera de jovens durante o término da pesquisa. Essa exceção, entretanto, não invalida a análise, pois o presbítero de jovens não assume nenhum dos bairros, é escolhido normalmente entre os mais jovens e, geralmente, não faz parte da Mesa do Conselho, ou seja, é hierarquicamente inferior aos demais presbíteros. $\mathrm{O}$ órgão máximo da comunidade só é plenamente acessível àqueles que estão no estágio mais interno do continuum que propus. 
Os membros do segundo estágio, intermediário, desempenham funções em diversas comissões e organizações atuantes na igreja ${ }^{17}$, porém estão sempre subordinados aos membros do Conselho, uma vez que estas comissóes são dirigidas invariavelmente por presbíteros ou pastores. Os grupos, que não são coordenados diretamente pelo Conselho, são de caráter mais recreativo e de pouco prestígio no todo da comunidade. Finalmente, os membros do primeiro estágio do continuum, mais externo, em geral não ocupam nenhuma função formal na organização da igreja.

Esse grupo, formado por jovens e cônjuges não-professos dos castrolandeses, é uma preocupação constante entre os membros daquilo que denominei como estágio mais interno do continuum fora-dentro na igreja. Prova disso é a existência, no Conselho, de um presbítero de jovens, eleito especialmente para esta função. Outra prova é que, durante o processo de substituição de pastores que presenciei, o critério máximo da comissão de escolha foi a habilidade no trato com os jovens. Em Castrolanda, os jovens ainda não-casados estão em situação de liminaridade na medida em que estão entre o "fora" e o "dentro". Pertencem à comunidade, mas não estão no seu centro, pois lhes falta ainda um ritual na vida comunitária, o Casamento.

\section{Relações de parentesco em Castrolanda}

O movimento de emigração que deu origem a Castrolanda teve algumas características notáveis e de conseqüências duradouras na organização social da colônia. Promovido pelas duas entidades não governamentais cristãs já citadas, esse movimento pôde se organizar, já na Holanda, em uma cooperativa provisória, a Cooperativa para Emigração em Grupo para o Brasil, por meio da qual extensas negociações com 
os governos brasileiro e holandês foram realizadas ${ }^{18}$. Cerca de 50 famílias com intenção de emigrar integraram essa cooperativa e freqüentaram as reuniōes promovidas inicialmente pelo Sr. Kaemingk, o diretor da Escola Cristã de Agricultura de Hoogeveen.

Cada uma dessas famílias era formada pelos futuros proprietários de um lote das terras adquiridas junto ao governo brasileiro e financiadas à cooperativa, constituindo uma "família pioneira" ${ }^{19}$, conforme a classificação local. Das 44 "famílias pioneiras" que apurei ${ }^{20}, 39$ eram compostas por um casal e seus filhos solteiros, três por homens solteiros, uma por um viúvo e seus filhos solteiros e uma por uma viúva e seus filhos solteiros $^{21}$. Cada uma constitui uma unidade distinta, a despeito das relações e do parentesco entre elas. Assim, Rieks Salomons e Henk Salomons, por exemplo, são irmãos e imigraram juntos, entretanto, constituem cada um com suas esposas e filhos uma "família pioneira" distinta, pois eram ambos casados no momento da imigração e possuíam cada um o seu próprio lote. Do mesmo modo, há três "famílias pioneiras" de sobrenome Groenwold: a de Teunis Groenwold, que imigrou viúvo com seus filhos, dois dos quais sendo casados e possuindo lotes próprios, e aquelas destes dois filhos (Jan Herman e Douwe) e suas esposas e filhos.

A chegada dessas 44 famílias ao Brasil se deu em seis grupos, entre novembro de 1951 e março de 1954, em viagens organizadas pela Cooperativa para Emigração em Grupo para o Brasil ${ }^{22}$. No primeiro navio, viajaram as famílias De Jager, Leffers, Pot e Dijkstra (estas duas últimas sem descendentes em Castrolanda). No segundo navio, que chegou ao Brasil em agosto de 1952, vieram as "famílias pioneiras" T. Groenwold, J. H. Groenwold, D. Groenwold, R. Salomons, H. Salomons, Moorlag, M. E. Borg e J. Wolters. 
O terceiro grupo, desembarcado em fevereiro de 1953, era composto por E. M. Borg, Kassies, Jan van der Vinne, Bouwman, Noordegraaf, Deen, Strijker, F. Wolters, Pals e A. L. Wolters. Em abril de 1953 chegou o quarto navio com as famílias R. Rabbers, L. Rabbers, Van Arragon, Van der Scheer, Jitse van der Vinne, Van der Beld, Bouwsema e Boessenkol. O penúltimo navio chegou em novembro de 1953 e nele vieram as famílias De Boer, Loman, Morsink (esposa e filhos mais novos vieram no último navio), Kiers e Nienhuis (esta última sem descendentes em Castrolanda). Finalmente, em março de 1954, chegaram as famílias Barkema, Mulder, Greidanus, Katerberg e Fokkema.

A esse grupo associado já na Holanda, juntaram-se outros imigrantes de origem holandesa que foram aos poucos se incorporando ao grupo original. Alguns deles, chegados pouco tempo após o sexto grupo, são também incluídos entre as "famílias pioneiras": Keegstra (1954), Epema (1954), Van Lonkhuijzen (1957) e Petter (1959). Além dessas, há mais dez famílias de imigração mais tardia ainda representadas em Castrolanda: Treur, Haasjes, Nienhuys, Hana, Withaar, Van der Riet, Van Santen, Van Nouhuys, te Vaarwerk e Zegwaard. Entre estas, apenas quatro (Haasjes, Van Santen, Nienhuys e Zegwaard) não estão ligadas por parentesco a alguma das 44 "famílias pioneiras".

As relações de germanidade, filiação ou aliança ligando membros de distintas "famílias pioneiras" são abundantes. Das 48 famílias apontadas acima (as 44 pertencentes à Cooperativa para Emigração em Grupo para o Brasil, acrescidas das quatro chegadas até 1959), 19 estão ligadas por relaçóes de parentesco próximo, que podem ser explicitadas conforme os quatro diagramas abaixo. 
O primeiro une as "famílias pioneiras" Kiers e Pot (a Sra. Kiers era irmã do Sr. Pot).

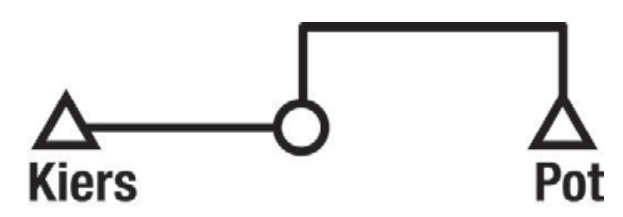

Diagrama 1 - famílias Kiers e Pot

O segundo grupo une as seis "famílias pioneiras" com sobrenome Groenwold, Rabbers e Moorlag (J. H. Groenwold, filho de T. Groenwold e irmão de D. Groenwold, é casado com uma filha da viúva Moorlag, enquanto seu irmão D. é casado com uma filha de R. Rabbers, irmã, portanto, de L. Rabbers.

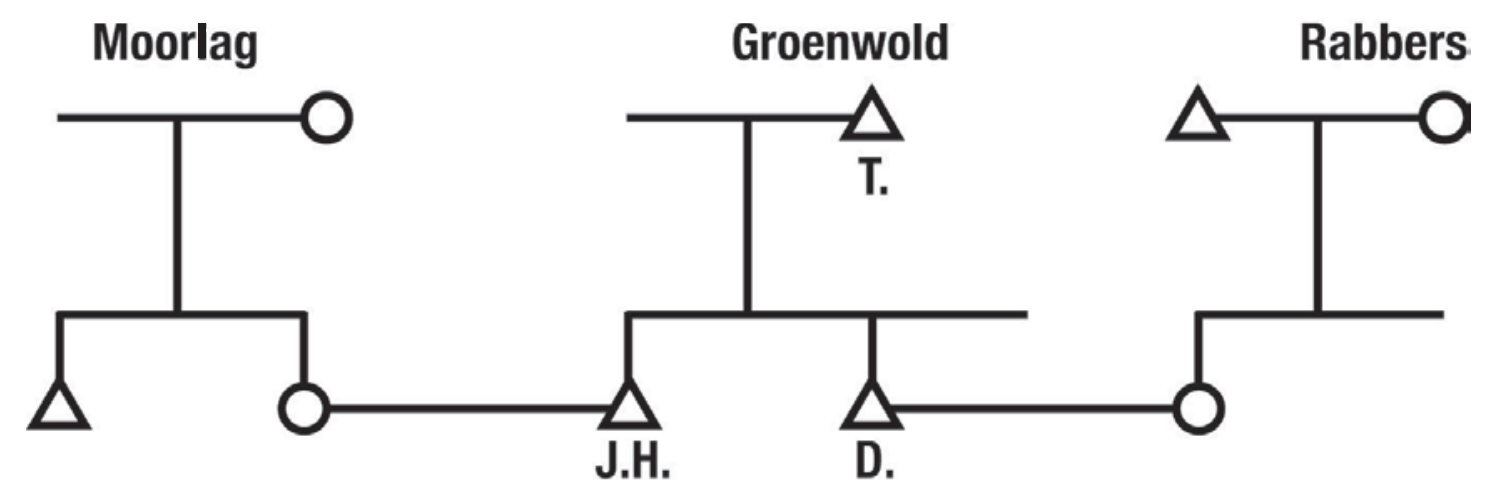

Diagrama 2 - famílias Moorlag, Groenwold e Rabbers 
O terceiro, mais numeroso, une as nove famílias pioneiras Borg, Salomons, Van der Vinne, De Jager, Leffers e Loman. (A Sra. Loman era irmã do Sr. Leffers. A Sra. Leffers era irmã dos dois irmãos Salomons. H. Salomons, J. de Jager e E. M. Borg eram casados com as três irmãs dos Van der Vinne. Finalmente, a esposa de Jan van der Vinne era irmã dos Borg.)

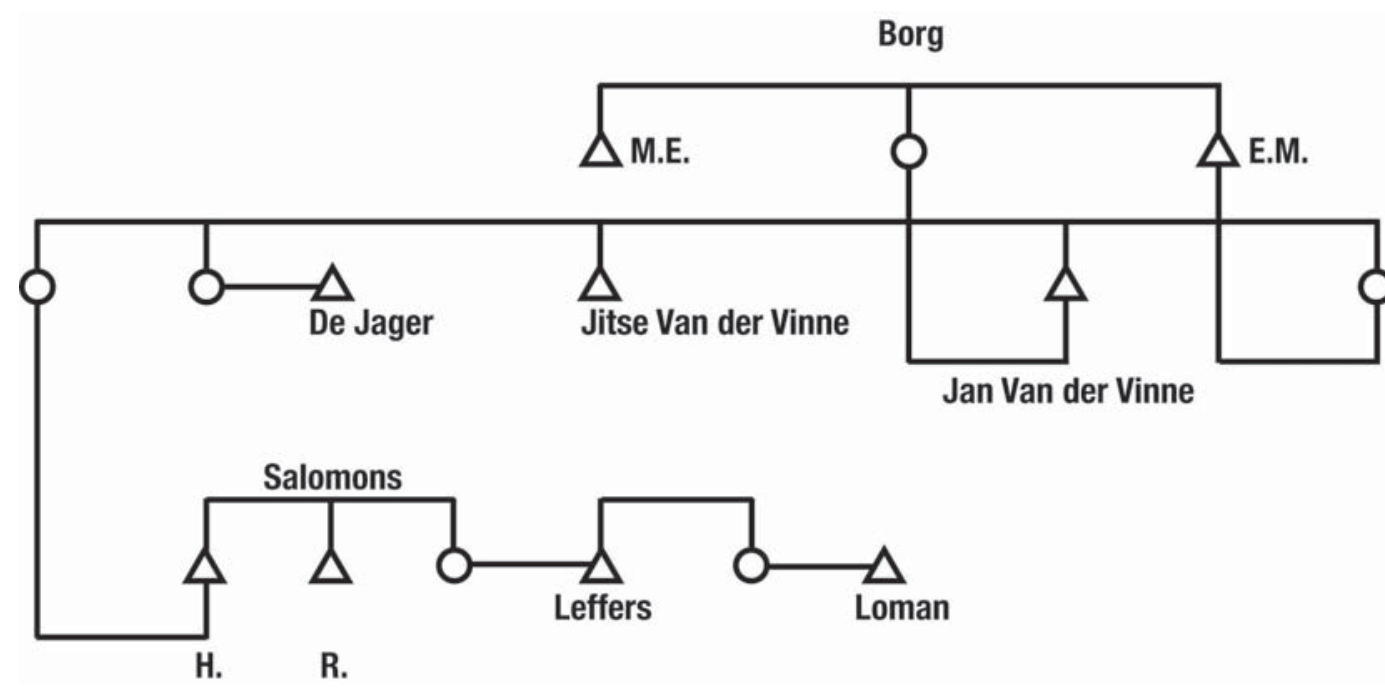

Diagrama 3 - famílias Borg, Van der Vinne, De Jager, Salomons, Leffers e Loman

O último une a família Fokkema à família Keegstra (Sra. Fokkema era irmã do Sr. Keegstra). As outras 29 "famílias pioneiras" vieram isoladas ou ligadas por parentesco mais distante.

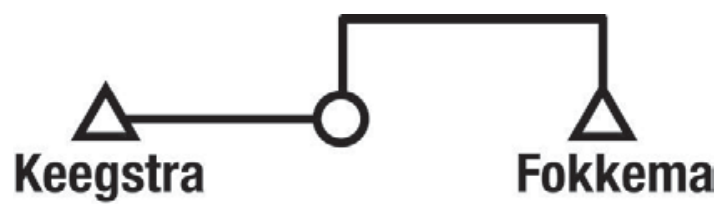

Diagrama 4 - famílias Keegstra e Fokkema 
Essa categoria local - a "família pioneira" - possibilita introduzir a questão da classificação em gerações, compreendendo a diferenciação entre a primeira e a segunda geração de imigrantes. À primeira geração pertencem os casais ou solteiros/viúvos chefes de cada uma das 46 "famílias pioneiras", chamados em Castrolanda de "pioneiros”. No caso da família Groenwold, por exemplo, tanto Teunis quanto seus filhos casados são incluídos na primeira geração, embora pertençam a gerações diferentes (pai e filhos). Há, assim, cinco pioneiros na família Groenwold: o viúvo Teunis, seus dois filhos casados e as esposas destes. Do mesmo modo, as filhas e os filhos solteiros de Teunis são considerados de segunda geração, embora sejam irmãos de Jan Herman e Douwe, que são de primeira geração. Um outro exemplo pode elucidar melhor essa classificação. Jacob Wolters imigrou para o Brasil solteiro, possuindo seu próprio lote, pertencendo portanto à primeira geração de imigrantes. Era, na época, noivo de Ida Moorlag, que imigrou com sua mãe viúva e seu irmão. Como sua mãe era a chefe da família, Ida é considerada membro da segunda geração. Caso Jacob e Ida tivessem se casado na Holanda, Ida pertenceria à primeira geração.

Esclarecido o critério para o estabelecimento da primeira geração, as gerações subseqüentes são compostas pelos filhos dos indivíduos da geração imediatamente superior. Assim, os filhos dos "pioneiros" integram a segunda geração, independentemente de terem nascido no Brasil ou na Holanda, os filhos deles, a terceira, e os netos, a quarta. Essa divisão em geraçôes tem certamente um rendimento sociológico que extrapola os limites do parentesco, entretanto de forma não muito rígida. Fora do domínio das relações familiares, a solidariedade entre esses grupos é descrita muito mais em termos de faixas etárias do que de grupos geracionais. Há quatro grupos etários que coincidem mais ou menos com as geraçôes. Assim, há o grupo dos "pioneiros", que são precisamente os membros da primeira geração, o dos "velhos", que já têm netos, e coinci- 
dem aproximadamente com a segunda geração, o grupo dos "casais jovens", que corresponde de forma aproximada à terceira geração, e os jovens e crianças, quase todos da quarta geração. Porém, entre os indivíduos mais jovens de uma geração e os mais velhos da geração imediatamente abaixo daquela não há grande distinção, e as divisões são bastante fluidas.

Das 48 "famílias pioneiras", 40 ainda têm descendentes (ou os próprios imigrantes) em Castrolanda. Algumas não resistiram às dificuldades dos primeiros anos da colônia, retornando à Holanda ou se estabelecendo em outras localidades. Outras desapareceram com o falecimento de todos os seus membros. No momento da finalização da fase de campo desta pequisa, no primeiro semestre de 2003, havia ainda 11 indivíduos da primeira geração vivos, todos com idade bastante avançada.

A segunda geração compreende todos os filhos dos pioneiros, nascidos na Holanda e imigrados solteiros com seus pais ou nascidos já no Brasil. Os indivíduos de segunda geração das 40 "famílias pioneiras", que ainda têm descendentes na colônia, totalizam 226 pessoas. Desses, 125 permaneceram em Castrolanda (23 já falecidos quando da realização da pesquisa), 29 mudaram-se para as outras colônias holandesas do Paraná (19 para Arapoti e dez para Carambeí) e 72 para outros locais.

Entre os 125 indivíduos da segunda geração que permaneceram em Castrolanda, 9 ficaram solteiros, sendo que seis atingiram a maturidade nesta condição e três faleceram antes de atingirem idade suficiente para o casamento. Dos 116 casados, 81 casaram com membros da própria geração (ou com pessoas pertencentes a uma das nove famílias posteriores aos pioneiros), seis casaram com castrolandeses de outra geração (três com pessoas da primeira geração, três com membros da terceira geração). Finalmente, 29 membros da segunda geração que permaneceram em Castrolanda se casaram com pessoas de fora da colônia, sendo nove de Carambeí, três de Arapoti, dois da Holanda e 15 "brasileiros". Entre aqueles que deixaram Castrolanda, é difícil fazer um levantamento dos 
casamentos. Consegui apenas apurar 16 uniōes ocorridas entre esse grupo, antes da saída da colônia, ou seja, 32 pessoas da segunda geração que deixaram Castrolanda casaram entre si. Outro dado notável sobre os casamentos na segunda geração é a expressiva freqüência de uniōes entre dois pares de germanos (cônjuge de ego é um germano do cônjuge do germano de ego). Trinta e dois indivíduos casaram-se desse modo, unindo oito pares de germanos (em quatro, ZH é WB para ego masculino e, em quatro, BW é WZ para ego masculino). Há, ainda, dois casos de casamentos entre primos, o primeiro com MZD e o segundo com MBD (ego masculino).

Sobre a terceira e a quarta gerações é bastante difícil levantar dados exaustivos e exatos, uma vez que o número de indivíduos é muito maior e sua mobilidade muito mais intensa. É possível, aqui, apenas apontar algumas tendências mais gerais, baseadas nos dados apurados dentro dos limites deste trabalho. A terceira geração, composta pelos filhos daqueles 125 membros da segunda geração que permaneceram em Castrolanda, compreende a maior parte dos casais jovens da colônia. Como, por definição, todos os membros da segunda geração se casaram no Brasil (pois aqueles casados já na Holanda eram de primeira geração), os membros da terceira geração são todos nascidos no Brasil, de pais aqui casados. O primeiro casamento celebrado na colônia foi o de Harm Rabbers e Antje Loman, em maio de 1954, do que se conclui que todos os membros da terceira geração tinham, no momento da pesquisa, menos de 50 anos. Portanto, a quarta geração é composta em sua maioria por crianças, e não há ainda nenhum casamento entre seus membros (embora uma criança de quinta geração já tenha nascido).

A partir do Guia da Comunidade (IER de Castrolanda, 2002), no qual estão listados todos os membros da igreja, cerca de 200 nomes da terceira geração puderam ser elencados, entre casados, solteiros e crianças estabelecidos em Castrolanda. Entretanto, uma parte considerável 
dos indivíduos da terceira geração vive fora da colônia e, embora seja difícil realizar uma contagem exaustiva, é possível afirmar, com base em depoimentos e estimativas dos próprios castrolandeses, que a porcentagem de membros desta geração que saíram de Castrolanda é provavelmente tão elevada quanto na segunda geração, ou seja, entre $40 \%$ e $50 \%$.

Foi possível fazer um levantamento de 84 casamentos na segunda geração, a maior parte deles de indivíduos que vivem na colônia. Entre esses, 19 se realizaram entre castrolandeses, 53 entre um castrolandês e um cônjuge "brasileiro" (34 de homens castrolandeses com mulheres "brasileiras" e 19 de mulheres castrolandesas com homens "brasileiros"), sete se deram com pessoas de Carambeí (seis de homens castrolandeses com mulheres de Carambeí e um de uma mulher castrolandesa com um homem de Carambeí) e cinco com holandeses (dois de homens castrolandeses com mulheres da Holanda e três de mulheres castrolandesas com homens holandeses).

Esses números apontam para algumas características notáveis da segunda e da terceira geraçôes. Primeiro, o elevado número de pessoas que deixou a colônia, imigrando para outras localidades (aproximadamente $45 \%$ para a segunda geração). As causas às quais os castrolandeses atribuem essa "diáspora" são, principalmente, duas. Primeiro, a escassez de terras próximas à colônia, que teria levado muitos dos filhos das numerosas famílias imigrantes a procurarem outras localidades para se estabelecerem. Este é, certamente, o caso da maior parte dos 29 indivíduos de segunda geração vivendo em Carambeí e Arapoti, cuja organização econômica é semelhante à de Castrolanda, baseada na produção agropecuária e no cooperativismo, além de parte dos 26 indivíduos que se estabeleceram em outras localidades ${ }^{23}$. Segundo, uma certa inadequação com o estilo de vida castrolandês é reputada como motivo para a opção por deixar a colônia. Essa inadequação é descrita geralmente em termos profissionais, familiares ou religiosos. 
Como já foi mencionado, praticamente todos os castrolandeses estão vinculados à atividade agropecuária, seja como proprietário de terras, seja como funcionário da cooperativa ou das unidades produtoras. O responsável pelas atividades produtivas nas chácaras e fazendas é o homem, e a cooperativa é tida como um ambiente predominantemente masculino, embora muitas mulheres também trabalhem nas chácaras e muitas auxiliem na gerência dos negócios e das contas. A atividade tida como de predominância feminina são os afazeres domésticos, o cuidado com os filhos e os trabalhos de artesanato variado (pintura em tecido, tela e porcelana, patchwork, trabalhos em bartante e manufatura de velas artesanais, entre outros), embora aqui, sobretudo no cuidado com as crianças, os homens também tenham com freqüência participação ativa $^{24}$. Assim, aqueles que não se adaptam a essas atividades, seja por desejo ou inclinação pessoal, seja por falta de meios para o trabalho agrícola - terra e capital -, acabam por se transferir para cidades maiores no Brasil ou na Holanda. A opção por viver em um ou outro país depende do tipo das oportunidades educacionais e profissionais disponíveis a cada indivíduo, e os castrolandeses não parecem atribuir grande importância a essa escolha. Os que se estabeleceram na Holanda são um grupo bastante restrito, formado majoritariamente por jovens da terceira geração (portanto, nascidos no Brasil) que residem em diferentes cidades holandesas, o que não caracterizaria um movimento expressivo o suficiente para ser interpretado como uma "migração de retorno". O que parece mais significativo, nesse caso, é o fato de o abandono da colônia ser motivado pelo leque de opçóes profissionais bastante limitado.

$\mathrm{O}$ aspecto familiar da inadequação ao estilo de vida de Castrolanda se manifesta tanto em relação a formaçôes familiares não reconhecidas ou não aceitas pelo grupo ${ }^{25}$, quanto em relação a casamentos chamados de "mistos" (aqueles nos quais um dos cônjuges pertence à colônia e o outro não), nos quais prevalecem os laços sociais do cônjuge vindo de 
fora em detrimento das relações internas da colônia. Nesses casos, ao invés de Castrolanda receber um novo membro, ela "perde" um indivíduo que se alia a outros círculos sociais. Assim, além daqueles que foram para longe estabelecendo suas vidas familiares de forma independente, há diversos exemplos de castrolandeses da segunda geração que vivem nas proximidades da colônia e passaram a se relacionar mais no meio social dos cônjuges do que na própria colônia.

Esse exemplo conduz, finalmente, ao aspecto religioso da inadequação ao estilo de vida castrolandês, pois o principal indicador da inclusão ou não de um indivíduo na colônia é sua presença entre os membros da Igreja Evangélica Reformada. Há descendentes de holandeses, membros da segunda ou da terceira geração, sócios da cooperativa, cujos filhos estudam na Escola Evangélica, e que vivem próximos à colônia que não são mais considerados membros plenos do grupo porque, por algum motivo, deixaram a igreja. No sentido oposto, há diversos exemplos de castrolandeses estabelecidos em outras cidades no Brasil ou na Holanda, sem nenhum vínculo com a cooperativa e raramente visitando Castrolanda, mas que, sendo ainda membros da igreja, são com freqüência mencionados e incluídos no grupo. E ainda, há diversas famílias de "brasileiros" residindo há muitos anos na região que são consideradas "pessoas de fora", pois não pertencem à IER.

Esses dados, acrescentados à questão já abordada acerca dos rituais da Igreja Evangélica Reformada como indicadores da pertença à comunidade, permitem introduzir a análise mais detalhada dos casamentos na segunda e terceira geração, uma vez que estes representam a única via de acesso de novos membros adultos à colônia. Na segunda geração, há a predominância das uniōes entre membros da colônia. Dos 116 indivíduos de segunda geração casados que permaneceram em Castrolanda, 87 casaram entre si ou com castrolandeses de outra geração, representando $75 \%$ do total. Os casamentos com "brasileiros" são apenas 15 , 
sendo nove de homens castrolandeses com mulheres "brasileiras" e seis de homens "brasileiros" com mulheres castrolandesas. Vale mencionar que entre os 15 cônjuges "brasileiros", sete (quatro mulheres e três homens) são de descendência alemã, a maioria deles oriunda da igreja luterana, ou seja, eles são também descendentes de imigrantes europeus protestantes. Entre os seis homens "brasileiros" casados com mulheres da segunda geração, apenas três não eram proprietários de terras na região, todos de casamento relativamente recente com algumas das representantes mais jovens desta geração.

Já na terceira geração, apesar de não ser possível dispor de dados totalizantes, pode-se observar que o número de casamentos com pessoas oriundas de fora da colônia é muito maior do que o de casamentos entre castrolandeses. Entretanto, isso não significa apenas que, de uma geração a outra, os castrolandeses passaram a se casar mais fora de Castrolanda, mas também e principalmente que mais indivíduos de fora foram incorporados à colônia.

É importante notar que os casamentos com indivíduos de fora da colônia na segunda e terceira geração, levados em conta aqui, referemse apenas àquelas pessoas que permaneceram em Castrolanda, e que muitos outros casamentos deste tipo ocorreram, uma vez que 101 indivíduos da segunda geração e um número também elevado da terceira deixaram a colônia, e que, entre estes, poucos casaram entre si. O fato é que, como visto, algumas pessoas deixaram Castrolanda justamente por terem casado fora dela, enquanto outros, cerca de $40 \%$ a $50 \%$ de cada uma das duas geraçôes, incorporaram seus cônjuges à colônia. Ou seja, os casamentos "mistos" acabam resultando, como já foi mencionado, no "ganho" ou na "perda" de um indivíduo. Assim, ou há o englobamento dos cônjuges vindos de fora, o que conferiria aos casamentos aparentemente exogâmicos um caráter de endogamia, ou há a saída de indivíduos da colônia. Por isso, o que não parece ocorrer, ou ocorre em 
poucos casos, é o estabelecimento de alianças entre grupos familiares castrolandeses e grupos familiares "brasileiros" por meio dos casamentos "mistos".

Assim, ao invés de caracterizar os casamentos como predominantemente endogâmicos na segunda geração e exogâmicos na terceira, como poderia supor uma análise apressada dos dados, seria possível estabelecer que a diferença entre as uniōes nestas duas geraçōes se dá apenas na forma como o grupo concebe a endogamia, com um considerável aumento, na terceira geração, das uniões com indivíduos oriundos de fora e englobados pelo grupo. O que ocorre é que na terceira geração, originada a partir de casamentos realizados predominantemente entre indivíduos da colônia, o número de uniões possíveis sem que se busquem cônjuges externamente é menor do que na segunda geração, uma vez que grande parte dos castrolandeses de terceira geração estão ligados por laços muito próximos de parentesco com seus pares. Essas uniōes com pessoas de fora, portanto, não poderiam ser caracterizadas como exogâmicas, pois elas não produzem alianças entre famílias castrolandesas e famílias "brasileiras". O englobamento dos indivíduos de fora opera uma mediação entre exogamia e endogamia, abrindo a possibilidade de realização de casamentos fora do grupo da colônia.

Desse modo, as possibilidades de um casamento que poderíamos denominar "castrolandês" estariam compreendidas entre dois limites: internamente, a proibição do casamento com parentes e, externamente, a necessidade de englobamento do cônjuge. Pelo lado interno, a proibição se estende até os primos (FGCh e MGCh) de forma não muito rígida (há dois casamentos deste tipo, como já foi mencionado). Os primos de segundo grau (FFGChCh, FMGChCh, MFGChCh e MMGChCh) não são reconhecidos como parentes e há diversos casos de uniões deste tipo. Pelo lado externo, o não englobamento do cônjuge acaba por resultar no afastamento social, pelo menos parcial, do casal. 
João F. Rickli. Religião e parentesco na colônia Castrolanda

Neste ponto, é possível estabelecer uma comparação entre alguns aspectos do parentesco em Castrolanda e a definição de "casa" elaborada por Lévi-Strauss (1979; 1983):

Estamos pois, sem dúvida, em presença de uma única e mesma instituição: pessoa moral detentora de um domínio composto simultaneamente por bens materiais e imateriais e que se perpetua pela transmissão do nome, da fortuna e dos títulos em linha real ou fictícia, tida sob a condição única de esta continuidade poder exprimir-se na linguagem do parentesco ou da aliança e, a mais das vezes, em ambas ao mesmo tempo. (Lévi-Strauss, 1979, p. 154)

A partir dessa definição, o autor demonstra ponto a ponto como a "casa" permitiria a combinação entre aspectos paradoxais: endogamia e exogamia, filiação e aliança, direito de voto e direito hereditário, hipergamia e hipogamia etc. Deixando de lado, por ora, a questão dos bens materiais, a ser tratada em publicaçôes futuras, seria possível utilizar a noção de casa como um modelo que permite compreender a Igreja Evangélica Reformada de Castrolanda como detentora de uma riqueza imaterial (simbólica), cuja transmissão e perpetuação se dá, em boa medida, por meio da linguagem do parentesco que, concebido como descrito acima, permite a combinação de exogamia e endogamia, filiação e aliança, em acordo com a definição levistraussiana. Os ritos do Batismo e do Casamento, como veremos adiante, expressam de diversas maneiras como é o parentesco que permite o ingresso de novos membros na igreja, marcando, portanto, este critério como determinante da transmissão dos bens imateriais da igreja. Do mesmo modo, a eleição de novos membros para o Conselho articula o direito de voto e o direito hereditário pois, se os cargos não são transmissíveis hereditariamente, as condiçôes de eligibilidade o são. 
Por outro lado, a dificuldade na criação de laços com pessoas (ou famílias) de fora, a menos que estes sejam incorporados à colônia, aponta para uma relação entre a esfera religiosa e a esfera do parentesco que poderia ser caracterizada como de englobamento hierárquico (Dumont, 1997; 2000a; 2000b), na qual a religião engloba o parentesco. Os vínculos de filiação e de aliança são reconhecidos em Castrolanda quando são ritualizados no Batismo e no Casamento. Os laços criados alhures, apartados da esfera religiosa, acabam por resultar na "perda" de um indivíduo, ou seja, na negação do vínculo ${ }^{26}$. A concepção, formulada acima, da IER como detentora de uma riqueza imaterial transmissível por meio do parentesco corrobora esse englobamento do parentesco pela igreja.

Nesse sentido, é também significativo o revezamento de mães, que tomam conta do Oppas (creche), e de duplas, para o café com os idosos do Lar Eben Hä̈zer ${ }^{27}$. A responsabilidade no cuidado com as crianças e os idosos da comunidade não é apenas da família, mas também da igreja. As regras que proíbem a participação simultânea de duas pessoas da mesma família no Conselho apontam ainda para uma transposição, para o domínio religioso, das regras de proibição do incesto.

Essa articulação entre religião e parentesco fica ainda claramente expressa nos ritos do Batismo e do Casamento. Ambos realizam a introdução de novos indivíduos na igreja e o fazem frisando a oposição hierárquica aqui tratada. Em ambos a família é destacada pela entrada ritualizada, junto com o pastor e o representante do Conselho, e por permanecer separada da comunidade, no primeiro banco da igreja. No Batismo, a comunidade se destaca reafirmando sua fé, recitando o Credo Apostólico, e respondendo afirmativamente à questão do pastor, assumindo a sua parte da responsabilidade pelo novo membro. Nos dois ritos, toda a comunidade cumprimenta a família no fim do culto, ritualizando a relação estabelecida entre religião e parentesco na inclusão de novos membros no grupo. 
Um último ponto a ser destacado trata das motivaçôes individuais e das atitudes em desacordo com a lógica comunitária personificada pelo par igreja/família. Na igreja, pensada por meio do modelo da "casa" levistraussiana, essas motivações individuais podem ser também compreendidas na linguagem do parentesco, ou seja, nessas escolhas matrimoniais até certo ponto livres. O grande motor dos conflitos e das mudanças nessa esfera é o elevado número de casamentos "mistos" e, portanto, de cônjuges "brasileiros" englobados pela colônia. Para possibilitar esse englobamento, a igreja, "detentora de um domínio composto simultaneamente por bens materiais e imateriais" (Lévi-Strauss, 1979, p. 154), é forçada a intensificar as trocas e a abrir mão de determinados símbolos. As mudanças do ponto de vista lingüístico são talvez a face mais visível dessa intensificação do comércio simbólico em favor de um aumento da possibilidade de englobamento ou incorporação de indivíduos de fora - o que significaria um aumento da possibilidade de casamentos realizados a partir de uma escolha individual, porém virtualmente endogâmicos.

A mudança, no campo do parentesco, seria constituída então no embate entre um núcleo "estrutural" - tratado aqui a partir do modelo da "casa" - e as estratégias e escolhas individuais, por ela englobadas. Cada casamento "castrolandês" é uma aposta - põe-se um indivíduo em jogo, para "ganhar" outro de fora, arriscando-se a sua "perda", como atestam os elevados índices de pessoas que deixaram a comunidade. Assim, a sociedade castrolandesa preservaria seu núcleo "estrutural" às custas da intensificação dos trânsitos simbólicos, processo mantido sob o cuidadoso controle da igreja. 


\section{Notas}

1 Este artigo foi elaborado a partir de dois capítulos de minha dissertação de mestrado, A "Comunidade da Bênção": religião, familia e trabalho na colônia Castrolanda, defendida no Programa de Pós-Graduação em Antropologia Social da Universidade Federal do Paraná, em julho de 2003. Agradeço a Marcos Lanna, meu orientador, a Ciméa Bevilacqua e Marta Amoroso, pelas valiosas contribuições que apresentaram como integrantes da banca, e a Sandra J. Stoll, cujo curso Rituais e Simbolismo foi fundamental para a elaboração deste texto.

2 Meus contatos com a colônia Castrolanda, que permitiram a realização do trabalho etnográfico, iniciaram-se em meados de 1999, quando fui indicado por um colega para substituí-lo como organista e "mestre-de-capela" da Igreja Evangélica Reformada, o que me possibilitou desde então freqüentar a colônia nos fins de semana e em estadias curtas. Posteriormente, em 2001, já como mestrando da UFPR, pude permanecer em Castrolanda por períodos mais longos, nos quais pude realizar de forma mais intensiva o levantamento etnográfico, sobretudo das questóes de parentesco, que possibilitou a realização deste artigo.

3 Utilizo aqui o termo brasileiro como categoria nativa, significando aqueles que não são imigrantes ou seus descendentes.

4 A análise dos dados castrolandeses por intermédio desse instrumental teórico pode apontar também para um modo peculiar de articulação entre religião e política, vistos a partir da dicotomia entre esfera doméstica e esfera pública. Essa questão e suas implicações deverão ser analisadas em artigo que se encontra em preparação.

5 A Sra. Kiers, uma das imigrantes da chamada primeira geração, organizou um livro sobre a colônia, lançado em holandês em 1991, durante as comemorações dos 40 anos da colônia. Esse livro foi revisto e relançado em português e holandês por ocasião dos 50 anos de Castrolanda (Kiers-Pot, 2001).

6 A reforma protestante na Holanda foi realizada de acordo com os princípios de Calvino - originário de Genebra, na Suíça. Com o passar dos anos, a igreja reformada holandesa foi se dividindo por questóes políticas e dogmáticas em denominações menores, das quais as três citadas são as mais importantes. Não cabe aqui explicitar as principais diferenças entre cada uma delas. Mas numa caracterização rápida, feita por um dos pastores holandeses em Castrolanda, pode-se dizer que a Christelijk Gereformeerde Kerk é mais conservadora e influenciada pelo movimento 
pietista, a Gereformeerde Kerk, mais progressista e aberta a mudanças, e a Nederlans Hervormde Kerk é mais antiga e tem um caráter mais oficial, sendo a igreja da família real. A grande maioria dos imigrantes que formaram Castrolanda pertencia a Gereformeerde Kerk.

7 Membro professo é aquele que já realizou sua profissão de fé, ritual que descreverei adiante, atingindo sua maioridade na vida eclesiástica.

8 A igreja conta, geralmente, com dois pastores contratados - um responsável pelas atividades em língua portuguesa e outro, em língua holandesa. $\mathrm{Na}$ fase final da pesquisa (início de 2003), a IER de Castrolanda contava com apenas um pastor devido ao falecimento do pastor Leonardo Los, em dezembro de 2002. O processo para a contratação de um substituto estava ainda em andamento.

9 As mulheres são elegíveis para o Conselho desde 1993. No período que observei, houve sempre cinco presbíteros e cinco presbíteras, entretanto, nenhuma diaconisa. Por três anos (1999-2001), a igreja teve uma pastora.

10 A divisão de Castrolanda em bairros só é reconhecida pela igreja, não havendo nenhuma outra esfera de atividade na qual a categoria "bairro" tenha algum significado. Alguns desses bairros sequer têm uma base territorial positiva, como aquele denominado "Castro", que reúne todos os membros da IER que não vivem dentro dos limites geográficos da colônia. Os moradores de Castrolanda, que não pertencem à IER, com quem conversei, desconheciam completamente essa divisão.

11 Os membros da igreja costumam se sentar sempre nos mesmos bancos, distribuídos por família. Até outubro de 2002, quando eles foram inteiramente estofados, por ocasião dos 50 anos da igreja, algumas pessoas deixavam almofadas em seus bancos de costume, marcando assim o seu lugar.

12 Uma doxologia é uma fórmula litúrgica cantada ou declamada após as bençãos e grandes oraçôes, na qual se glorificam a grandeza e a majestade divinas.

13 O Credo Apostólico é uma fórmula litúrgica de declaração dos princípios da fé cristá.

14 Nas igrejas protestantes reformadas há somente esses dois sacramentos. O Casamento, a Profissão de Fé e a Ordenação de novos pastores, embora sejam ritos importantes, fazem parte dos chamados "Atos Pastorais", que só podem ser ministrados por um pastor ordenado, não sendo considerados sacramentos.

15 Refiro-me aqui exclusivamente ao Batismo, ao Casamento e à Profissão de Fé da IER de Castrolanda, e as definições de não-batizado, não-casado e não-professo 
equivalem a não-batizado em Castrolanda, não-casado em Castrolanda e não-professo em Castrolanda.

16 Obviamente, este grupo inclui os imigrantes que, nascidos e batizados na Holanda, fundaram a IER Castrolanda.

17 Essas diversas organizaçôes estão reunidas abaixo de duas comissões principais: o Departamento de Educação Cristã (DEC), responsável pelas atividades educacionais da igreja, e a Associação de Assitência Social de Castrolanda (AASC), que coordena os trabalhos filantrópicos e assistenciais da comunidade.

18 Os detalhes das negociações acerca da exportação de bens de capital e da obtenção de crédito favorável para a aquisição de terras e implementos estão descritos no texto da palestra proferida pelo Sr. Rieks Salomons, por ocasião dos 30 anos da colônia (Kiers-Pot, 2001, p. 252-61).

19 Com exceção das famílias M. E. Borg e Morsink, que tinham apenas os lotes residenciais no centro e eram, respectivamente, o mecânico e o padeiro da colônia.

20 Para o levantamento dessas primeiras "famílias pioneiras", baseei-me no livro da Sra. Kiers (Kiers-Pot, 2001, p. 18-89) e em depoimentos de imigrantes mais idosos. Como algumas das famílias retornaram à Holanda ainda nos primeiros anos do estabelecimento da colônia, é difícil reconstituir com exatidão os dados acerca desse período. O levantamento exaustivo das fontes que confirmem esses dados é tarefa para um estudo histórico e ultrapassa os objetivos deste trabalho.

21 Note-se no termo "família pioneira", na categorização local, incluem-se também homens solteiros.

22 Estão listadas aqui apenas 40, pois não consegui apurar a data exata da chegada de algumas das famílias que retornaram à Holanda logo nos primeiros anos da colônia.

23 Entre essas outras localidades há regióes como Maracaju (MS), onde uma espécie de segunda colônia se constituiu, baseada na agropecuária, grandes cidades como São Paulo e Curitiba, ou ainda outros países (Canadá, sobretudo), focos de imigração holandesa.

24 Os variados aspectos do trabalho em Castrolanda são abordados no quarto capítulo de minha dissertação de mestrado (Rickli, 2003).

25 Como exemplo dessas formaçães não reconhecidas pelo grupo, pode ser citado o caso de alguns indivíduos de orientação homossexual que optaram por viver na Holanda ou em grandes cidades no Brasil. 
26 Talvez o exemplo que encontrei em campo que melhor evidencia esse processo ocorreu durante o levantamento da genealogia de uma das "famílias pioneiras". Conversando com diversos indivíduos da segunda geração dessa família, eles deixavam de contar como irmã uma senhora que se converteu ao catolicismo por ter se casado com um fazendeiro de Castro. Embora eles vivam muito próximos da colônia e tenham um bom relacionamento com seus parentes, estes deixaram de reconhecer (formalmente) o vínculo de germanidade na ausência de um vínculo religioso. Essa senhora é contada entre aqueles que deixaram a colônia, embora viva a poucos quilômetros de lá.

27 Há listas publicadas no boletim mensal da igreja, nas quais são escaladas cinco mães, para cuidar das crianças pequenas durante o culto, e duplas, para tomar café, às terças-feiras, no Lar Eben Haëzer, onde reside a maior parte dos idosos da colônia.

\section{Bibliografia}

DUMONT, L.

Homo Hierarchicus: o sistema de castas e suas implicações, São Paulo, Edusp.

2000a Homo Aequalis: gênese e plenitude da ideologia econômica, Bauru, Edusc.

2000b O individualismo: uma perspectiva antropológica da ideologia moderna, Rio de Janeiro, Rocco.

IGREJA EVANGÉLICA REFORMADA DE CASTROLANDA

2002 Guia da Comunidade, Castrolanda.

KIERS-POT, C. H. L.

$2001 \quad$ Castrolanda 50 anos: 1951-2001, Castro, [s.n.].

LÉVI-STRAUSS, C.

1979 A via das máscaras, Lisboa, Editorial Presença/Martins Fontes.

1983 "Histoire et Ethnologie", Annales ESC, Paris.

RICKLI, J. F.

2003 A "Comunidade da Bênção": religião, familia e trabalho na Colônia Castrolanda, Curitiba, UFPR, 93pp. 


\begin{abstract}
This article seeks to draw a systematic picture of the relations between religion and kinship in Castrolanda, a colony made up of dutch immigrants in the countryside of Paraná State. It describes some rituals of the local church and some aspects of kinship, like the division of the families in four generations, the criteria for this division, and the pattern of marriages and alliances inside every generation. Through these descriptions, the present text seeks to explain the relationship beetwen kinship and religion, supported by theoretical considerations such as the notion of maison and the notion of hierarchical encompassment.
\end{abstract}

KEY-WORDS: religion, kinship, maison, hierarchy.

Aceito em novembro de 2004. 